\title{
UN NUEVO PARADIGMA DEL ESTADO UNITARIO: LA ASIMETRÍA TERRITORIAL Y LOS ESQUEMAS DE COORDINACIÓN*
}

\section{A NEW PARADIGM OF THE UNITARY STATE: TERRITORIAL ASYMMETRY AND COORDINATING SCHEMES}

\author{
Vanessa Suelt Cock**
}

Fecha de recibido: 3 de julio del 2013 Fecha de aceptación: 30 de julio del 2013

\section{Para citar este artículo / To cite this article}

\author{
Suelt Cock, Vanessa, Un nuevo paradigma del estado unitario: la asimetría \\ territorial y los esquemas de coordinación, 127 Vniversitas, 309-339 (2013) \\ doi:10.1144/Javeriana.VJ127.npeu
}

* El presente artículo es producto del Grupo de Investigación de Derecho Público de la Pontificia Universidad Javeriana y del proyecto de investigación aprobado por la Vicerrectoría de Investigación: "La autonomía regional y local una visión comparada, aportes para el caso colombiano".

** Abogada y especialista en derecho administrativo, Pontificia Universidad Javeriana. Doctora en Derecho Público la Universidad de Salamanca, España. Profesora investigadora y directora del Grupo de Estudios en Derecho Público, Pontificia Universidad Javeriana. Correo electrónico:vsuelt@javeriana.edu.co 


\section{RESUMEN}

Este artículo se propone destacar la importancia de la utilización de esquemas territoriales acordes con las situaciones sociales, económicas y culturales colombianas, permitiendo una configuración de autonomía política en el que se reconozca un margen de gobierno para la atención de los propios intereses locales y su defensa. Ello se presenta a partir de la comprensión del marco conceptual del Estado federal y los nuevos conceptos de arreglos federales. Con ello puede comprenderse la idea de proceso en la configuración de los diseños territoriales en donde el reconocimiento de alternativas territoriales para las poblaciones diversas es fundamental, pero también encontrar esquemas de cooperación, articulación y de solidaridad entre entidades territoriales. Con ello podrá romperse la rigidez del Estado unitario colombiano, y permitir que sean los territorios los que conduzcan sus intereses una vez que ellos han podido identificarlos.

Palabras clave autora: Diseño territorial, autonomía, arreglos federales, diversidad territorial, pluralidad territorial en Colombia.

Palabras clave descriptor: Autonomía, pluralismo- Colombia, territorialidad humana, Ordenamiento territorial-Colombia. 


\section{ABSTRACT}

This article aims at highlighting the importance of using territorial schemes in accordance with social, economic and cultural situations in Colombia, allowing the configuration of political autonomy in which a government margin is recognized for the care of local interests and its own defense. This comes from the understanding of the conceptual framework of the federal state and the new concepts of federal arrangements. This contributes to understand the idea of process in shaping territorial designs in which recognition of territorial alternatives for diverse populations is essential, but also find forms of cooperation, coordination and solidarity among local authorities. This may break the rigidity of the Colombian unitary state, and allow the territories to be the ones leading their interests once they have been identified.

Keywords author: Territorial design, autonomy, federal arrangements, territorial diversity, territorial pluralism in Colombia.

Keywords plus: Autonomy, pluralism-Colombia, human territoriality, spatial planning-Colombia.

\section{SUMARIO}

INTRODUCCIÓN.- I. EL DISEÑO TERRITORIAL DE UN ESTADO.- II. LA FLEXIBILIDAD CONCEPTUAL DEL FEDERALISMO.- A. Arreglos federales.- B. La asimetría.- III. EL PROBLEMA DE LA AUTONOMÍA EN LA LEY ORGÁNICA DE ORDENAMIENTO TERRITORIAL.- A MODO DE CONCLUSIÓN: LA SUPERACIÓN DE LA RIGIDEZ DEL ESTADO UNITARIO, LA ALTERNATIVA AUTONÓMICA DE LOS TERRITORIOS DIVERSOS. 


\section{INTRODUCCIÓN}

La organización territorial de un Estado ha variado a lo largo de la historia; en el siglo XVIII y hasta la primera parte del siglo XX predominó el Estado unitario. El modelo del Estado nación europeo tenía esta configuración, salvo algunas organizaciones que mantuvieron una organización en donde predominaba la idea federal $^{1}$. El concepto jurídico de Estado federal sería construido por la dogmática alemana del siglo XIX, la que contribuiría a la generalización del término ${ }^{2}$. El siglo $\mathrm{XX}$ ve un auge de la forma federal, diferentes constituciones se nominan federales o configuran estructuras compuestas en las que se deja un amplio margen para la configuración de entidades sub-estatales que tengan un grado de autonomía. Ello ha sido comprendido por un sector doctrinal como arreglos federales. Esta forma de flexibilizar la configuración de organización territorial que se presenta después de la Segunda Guerra Mundial también afecta a los Estados unitarios. Así, el Estado unitario clásico como el francés, también comienza a comprender la posibilidad de la flexibilidad territorial en el reconocimiento diverso de autonomías a las entidades sub-nacionales. Esto es posible, en parte, por el reconocimiento jurídico que se realiza de las asimetrías, es decir, de diferencias económicas, sociales, políticas y culturales entre los estados, regiones, provincias, que requiere una aproximación diversa en el gobierno del territorio ${ }^{3}$.

1 El profesor Elazar señalaría que la idea federal es milenaria y data de la organización en el antiguo Israel, hace más de 3.200 años, y las confederaciones existentes en lo que hoy es Grecia y Asia Menor. Confederaciones como las de las tribus beduinas, así como las tempranas ligas de ciudades-estado helenas diseñadas para facilitar el comercio y la defensa común. En América los nativos de Norteamérica funcionaban bajo el sistema confederal. Daniel J. Elazar, Federalism: An Overview, Pretoria, 19 (1995).

2 La denominación de Estado federal, como señala el profesor García Pelayo, se utiliza por primera vez en la Confederación Renana. Son las formulaciones teóricas producidas en Alemania, a lo largo del siglo XIX, las que dan al Estado Federal una connotación precisa que permite diferenciarlo de la Confederación, contribuyendo de este modo a la generalización del término. Manuel García Pelayo, Derecho constitucional comparado, Alianza, Madrid, 216 (1987). Para ver el tratamiento extenso de la teoría federal y diversos análisis sobre el mismo ver entre otros: Vanessa Suelt Cock, El federalismo en teoría y práctica, el caso español un proceso federal, Juruá editores (2010). La influencia del federalismo competitivo en el nuevo régimen local español, 12 Revista de estudios socio jurídico, No. 1, Universidad del Rosario, Bogotá, 199-232 (2010).

3 Charles D'Tarton, Simetría y asimetría como elementos del federalismo: una especulación teórica, en: Enric Fossa \& Ferrán Requejo, Asimetría federal y Estado plurinacional. El debate sobre la acomodación de la diversidad en Canadá, Bélgica y España, Editorial Trotta, 26 (1999). 
Estas asimetrías pueden comprender la idea de naciones plurales o de derechos constitucionales diversos para garantizar o permitir la manifestación de la pluralidad territorial, como el caso de España, Bélgica, Canadá ${ }^{4}$ de los reconocimientos de las regiones y de las entidades sui generis en Francia y Alemania, que tras las reformas constitucionales del 2006, señalan que los estados federados puedan separarse de lineamientos jurídicos señalados por el Estado central ${ }^{5}$.

La flexibilidad o la diversidad de la configuración de la organización territorial se puede observar en los Estado federales, esto está presente en los diversos grados de autonomía que en este tipo de Estado se pueden reconocer y que dan cuenta de la diversidad económica, cultural, política; mientras que la rigidez en el desarrollo de esa autonomía se presenta en los Estados unitarios en donde estos grados de autonomía se han reconocido con mayor timidez y están sujetos a los conceptos de unidad, soberanía y centralización del poder legislativo. Frente a ello, Jellinek, a principios del siglo XX, observaba la presencia de "fragmentos de Estado" tipos de configuración territorial que presentaban en la realidad, y que no encajaban dentro de las características de la teoría estatal. Otro autor más contemporáneo, como Elazar, señala que el Estado federal es solo una de las amplias formas en que pueden configurarse las estructuras compuestas de un Estado. La flexibilidad territorial que permite un Estado federal puede facilitar las soluciones de problemas étnicos, económicos y de gobierno en un determinado territorio ${ }^{6}$. De este modo, grandes extensiones territoriales como Rusia e India han acudido a esta forma de organización. Las expresiones de los arreglos federales pueden comprender el reconocimiento de idiomas, estructuras económicas, sociales y culturales diversas, así como constituir soluciones en el marco de un conflicto armado. La idea de la homogeneidad del Estado nación moderno ha sido superada, no solo desde la realidad del Estado compuesto

4 Ibíd.

5 En mayo 2006 el Comité de derecho del Bundestag y del Bundesrat estudian la propuesta de reforma, y acuerdan los cambios. En septiembre del 2006 entran en vigencia los cambios en la Ley Fundamental y de algunas leyes que la acompañan. Hans Gerd Pieper, Staats organisationsrecht, Alpmann Schmidt, Auflage, 161 (2007).

6 Así lo ha señalado Ronald L. Watts, en: Comparing Federal Systems, Institute of Intergovernmental Relations, Queen's University Kingston, Canadá, 3 (1999) y Elazar en: Federalism an overview, Pretoria 19 (1995), entre otros, como una de las ventajas del federalismo y que vía de ejemplo puede citarse a India, Rusia, Suráfrica. 
con las diversas expresiones de los arreglos federales, sino desde los Estados unitarios con el reconocimiento diverso en el territorio. Así se comprende que Francia haya reconocido las comunidades de ultramar con derechos de participación política, así como las entidades sui generis?

En este escenario de la realidad estatal, el presente artículo se propone destacar que a pesar de la rigidez de la dogmática estatal respecto de la concepción de los Estados unitarios, la flexibilidad está comenzando a reconocerse y cómo ella puede ser una expresión de los intereses de la comunidad local, así como de su diversidad cultural y del contacto con el territorio. Los desarrollos diversos de la configuración jurídica en el territorio destacan la importancia de la utilización de esquemas territoriales acordes con las situaciones sociales, económicas y culturales; este es el caso de los municipios con home rule en Estados Unidos. En el caso colombiano, es posible comprender una configuración de la autonomía política de segundo grado, es decir, una capacidad de autogobierno para dirigir políticamente a un territorio que no compone potestad legislativa en el que reconozca un margen de gobierno para la atención de los propios intereses locales y su defensa ${ }^{8}$. Estas propuestas, lejos de romper la unidad nacional, la afianzan, pues las configuraciones territoriales se diseñan y refuerzan para solucionar los problemas que acarrea la diversidad. Estos reconocimientos permiten una reconfiguración de la unidad, no sobre la base de la homogeneidad, sino sobre el de la negociación y la diferencia9.

De acuerdo al marco anterior, el artículo se propone explicar los conceptos del diseño territorial de un Estado, la flexibilidad conceptual del federalismo, el concepto de los arreglos federales y el reconocimiento de las asimetrías. Para ello se tendrá como fuente de comparación el caso de Estados Unidos y Alemania,

7 Ver la comparación entre los desarrollos del Estado Unitario francés, Italia y España. En: Vanessa Suelt Cock, La organización territorial colombiana frente a la tendencia de configuración federal, 10 Revista de Estudios Socio Jurídicos, No. 1, 155-200 (2008).

8 Por ello denomina de segundo grado a diferencia de la presente en los Estado federal y regionales. Ver al respecto: José Luís Carro Fernández-Valmayor, El debate sobre la autonomía municipal, Revista de Administración Pública, No. 147, $59-95$ (sep.-dic., 1998). Ver al respecto: Federalismo en teoría y práctica, El caso español como proceso federal, estudio de la autonomía regional y local en los sistemas federales, Juruá, 228 y ss. (2010).

9 Ver al respecto: Antonio La Pergola, Los nuevos senderos del Federalismo, Centro de Estudios constitucionales, Madrid, 13 y ss. (1994). 
y la doctrina más relevante en estos países $^{10}$; sobre esta base se presenta un análisis de cómo a pesar de la rigidez de la normativa territorial colombiana, la realidad está dando paso a comprender expresiones diversas en los territorios, presente en el Estado unitario colombiano y una reflexión sobre los reconocimientos diversos de autonomía, así como propuestas para mejorar la articulación entre el gobierno central y los gobiernos periféricos.

\section{EL DISEÑO TERRITORIAL DE UN ESTADO}

La dogmática constitucional ha comprendido el diseño territorial respecto de tres tipos de Estado: el unitario, el regional y el federal. Así, mediante la Constitución se reparte el poder político y económico de un Estado a través de las competencias que residen en el órgano central y las que le quedan a los entes sub-estatales o les son otorgadas a estos ${ }^{11}$. La configuración de los Estados modernos en el marco de las estructuras señaladas fue uno de los asuntos más conflictivos, pues esta entraña la división del poder sobre la base territorial. La dogmática constitucional no da cuenta de la compleja realidad estatal, ni de los conceptos que preceden o se mantienen tras una definición del diseño territorial. Ello puede comprenderse de lo que sostuvo a finales del siglo XIX Jellinek, en su escrito Fragmentos de Estado: "las configuraciones estatales emanan de la experiencia, están esencialmente condicionadas a la realidad de la existencia estatal. Pues los conceptos jurídicos no son esencias trascendentales [...] sino tipos, contenidos en circunstancias vitales carentes frecuentemente de lógica. Por eso no es la mejor doctrina de Derecho Público aquella que ofrece la mayor perfección lógica, sino la que explica la realidad política de manera más natural”. La investigación jurídica debe ser constantemente renovada, pues el Estado sufre un "proceso continuo de transformación"12.

10 Se elige estos países por ser dos casos clásicos de Estado federal donde se ha dado paso a esquemas cooperativos y también al reconocimiento de asimetrías.

11 Carl J. Friedrich, Limited Government: a comparison, Harvard University - Prentice-Hall, Inc - Englewood Cliffs, New Jersey, 21 (1974). Ver al respecto: Suelt Cock, La organización territorial colombiana frente a la tendencia contemporánea de configuración federal, op. cit., $158-200$.

12 Georg Jellinek, Fragmentos de Estado, op. cit., 54. 
Esta premisa de Jellinek ha sido complementada por otros tratadistas del derecho público y de la ciencia política. Respecto a los primeros debe destacarse lo señalado por Antonio La Pergola, quien indica que el federalismo es estructura y proceso a la vez ${ }^{13}$. Sobre las estructuras estáticas diseñadas por los juristas, tiene lugar una evolución de este tipo de organización territorial, presentándose diferentes fenómenos federales que responden a las concretas circunstancias históricas, sociales, políticas y económicas de cada comunidad. Y una vez constituido el sistema federal empieza un proceso en continua transformación. Tal como han observado los politólogos, un proceso dinámico. Ello hace necesario, para los juristas, una adaptación de los viejos dogmas a los nuevos procesos en curso $^{14}$. En el campo de la ciencia política debe destacarse a Daniel Elazar, quien sostuvo que el mundo se encontraba ante un cambio de paradigma del Estado, figura predominante del Estado nación en el siglo XIX y principio del siglo XX, hacia el federalismo, fenómeno más flexible que se adapta de mejor modo a las circunstancias diversas y complejas del mundo contemporáneo ${ }^{15}$.

En este escenario debe tenerse en cuenta que Francia inicia a finales de los años cincuenta un proceso de reforzamiento territorial a partir del reconocimiento de la región, en una primera instancia como entidad administrativa y después con características de región política. Ello también reconfigura el imaginario del Estado unitario clásico francés como una inamovible homogeneidad hacia una reconocimiento de la pluralidad, sin la cual no podrían cerrarse las distancias económicas y sociales entre territorios o, lo que es más importante, una integración entre los mismos, sus mercados y el reconocimiento de su diversidad cultural. De igual modo ha sucedido en Italia, España y Alemania ${ }^{16}$.

13 Antonio La Pergola, Los nuevos senderos del federalismo, op. cit, 15.

14 Ibídem, 18 y 208-209.

15 Daniel Elazar, From Statism to Federalism A paradigm Shift, 17 International Political Science, No. 4, 417-429 (1996).

16 Este tipo de entidad territorial hace su aparición en el sistema francés mediante los decretos de 30 de junio de 1955 y de 2 de junio de 1960. La región no estaba prevista por la Constitución de 1958. El 5 de julio de 1972 se modifica en parte el título constitucional de ordenación regional, pero sin cambiar el enfoque que se le había dado en los años sesenta, de regiones administrativas a las que se les atribuye competencias de preparación para la elaboración del programa económico nacional. La leyes de 1982 y 1983 continuarían con este proceso hasta la reforma constitucional del 17 de marzo de 2003, del título XII de la Constitución, "De las colectividades territoriales". Ver al respecto: Vergottini, Regiones y Estado en la dinámica 
En definitiva, deben tenerse en cuenta los elementos estructurales de la dogmática constitucional y su funcionabilidad en la realidad estatal, las estructuras jurídicas deben estar al servicio de la problemática estatal, ser flexibles para poder surtir los conflictos existentes y permitir la pluralidad territorial. Los diseños territoriales deben ser comprendidos como un proceso en el que pueden reforzarse y reconocerse diversas unidades sub-estatales con diversos grados de autonomía, con ello se podrá lograr intereses comunes y cerrar brechas económicas entre territorios y así garantizar un mínimo de condiciones para los habitantes de todas las zonas en un marco estatal ${ }^{17}$.

Ahora bien, ello por supuesto tiene en el marco constitucional unos límites; en un Estado unitario pueden reconocerse autonomías políticas de segundo grado, es decir la posibilidad de conducir políticamente a los territorios en el marco de la ley, y con ello presentar políticas públicas diversas de la política nacional. Es el caso de las grandes ciudades, por ejemplo París, y en el caso latinoamericano Bogotá, entre otras ${ }^{18}$, que cuenta con un régimen especial que le da un margen de maniobra para la defensa de sus intereses, y le proporciona contenidos de autonomía local más amplios que los del resto de los distritos y municipios en Colombia ${ }^{19}$. Es necesario resaltar que las ciudades tendrán una autonomía de contenido más amplio en los Estados como los federales o los regionales ${ }^{20}$,

institucional. Consideraciones comparadas, Revista Vasca de Administración Pública, No. 14, 8 y ss. (1986). Vergottini, Derecho constitucional comparado, Espasa-Calpe, Madrid, 265-275 (1983). La Pergola, Federalismo y regionalismo: el caso italiano, en: Gumersindo Trujillo, Coord., Federalismo y regionalismo, Centro de Estudios Constitucionales, Madrid, 165-196 (1979). Loewenstein, Teoría de la Constitución, Ariel, Barcelona, 364 y ss. (1982), La Pergola, Los nuevos senderos del federalismo, Centro de Estudios Constitucionales, Madrid, 293 y ss. (1993), Peter Häberle, El regionalismo como principio estructural naciente del Estado constitucional y como máxima de la política del derecho europeo, en: Iñaki Herrarte Lasagabaster, Ed., Retos actuales del Estado constitucional, Instituto Vasco de Administración Pública, Oñati, 47 y ss. (1996). El desarrollo comparativo de la temática en Vanessa Suelt Cock, La organización territorial colombiana frente a la tendencia contemporánea de configuración federal, op.cit., en donde está la bibliografía al respecto.

17 Esto lo señalaba ya Georg Jellinek, Fragmentos de Estado, op. cit., 54.

18 Ver al respecto, el tratamiento de Vanessa Suelt Cock et. ál.: La autonomía local en diversos sistemas de organización, un marco conceptual para el análisis del caso colombiano, Vniversitas, No. 122, 117-168 (2011).

19 De acuerdo a su marco legal de actuación contenidos en el Decreto 1421 de 1993

20 Los reconocimientos de la autonomía responden al marco estatal, es decir, en Estados unitarios se reconoce una autonomía administrativa o política de segundo grado. En Estados federales se reconoce una autonomía de primer grado (facultad legislativa) en primera instancia a los estados miembros e incluso a nivel local. Esta conclusión se alcanza después de hacer 
permitiendo varios elementos que hacen de esta autonomía un verdadero gobierno local y es: la participación de los interesados en las decisiones; el reconocimiento de la pluralidad y diversidad en cada entidad sub-estatal, la posibilidad de innovación para obtener recursos propios, y su propia regulación de la autonomía. Elementos todos que son más difíciles de realizar en un Estado unitario en el que la autonomía administrativa implica una subordinación al Estado central y muy poca participación, recursos e innovación en políticas públicas en sus ámbitos competenciales ${ }^{21}$. Por ello si el Estado unitario no cuenta con elementos de articulación y coordinación del poder central con los poderes territoriales, en donde se tomen decisiones de manera conjunta para atender intereses generales, estas características se acentúan, mientras que, por el contrario, serán menos rígidas si se cuenta con estos mecanismos, como se explicará más adelante.

\section{LA FLEXIBILIDAD CONCEPTUAL DEL FEDERALISMO}

El siglo XX ve un auge de la forma federal, un gran número de Constituciones se nominan federale ${ }^{22}$ y se configuran diversos esquemas bajo esta nominación ${ }^{23}$. El incremento de la organización federal lleva consigo la búsqueda de otros criterios explicativos de

un estudio comparativo de los reconocimientos de la autonomía local en Estados Unidos, Alemania y España. Ver al respecto: Vanessa Suelt Cock, El federalismo en teoría y práctica, el caso español como proceso federal, Juruá (2010). Vanessa Suelt Cock et ál., La autonomía local en diversos sistemas de organización, un marco conceptual para el análisis del caso colombiano, op. cit.

21 Ver al respecto: Vanessa Suelt Cock, La organización territorial colombiana frente a la tendencia contemporánea de configuración federal, op. cit.

22 En 1955 Arthur W. Macmahon escribe que el 40\% de la población vive en países cuyas constituciones se nominan federales. Federalism: Nature and emergent, Garden City, New York, Doubleday (1955). Afirmación que retoma Elazar en sus trabajos sobre federalismo, concretamente en Federal systems of the world: a handbook of federal, confederal and autonomy arrangements, Jerusalem Institute for Federal Studies, Comp. and Ed. Daniel J. Elazar, Longman, London (1991).

23 La mayoría de estas nuevas federaciones o cuasi-federaciones en términos de Wheare fueron fundadas en Asia. Ente ellas: Indochina (1945), Burna (1948), Indonesia (1949), India (1950), Pakistán (1956), Malaya (1948), y Malasia (1963). En el medio este las Unión de Emiratos Árabes (1953), Nigeria (1954), Mali (19599, el Congo (1960), Camerún (1961) y Comorros (1978). Entre las federaciones fundadas y algunas restauradas están: Austria (1945), Alemania (1949), Yugoslavia (1946), y Checoslovaquia (1970). En Sur América, Brasil (1946), Venezuela (1947) y Argentina (1949). Ronald L. Watts, Comparing Federal Systems, Institute of Intergovernmental Relations, Queen's University Kingston, Ontario, Canadá, 3 (1999). 
la realidad federal: el federalismo permite el análisis de la organización territorial a partir de la configuración del poder, así puede dar paso a una amplia gama de realizaciones ${ }^{24}$.

El federalismo, como organización de poder, es una especie particular de división de poderes ${ }^{25}$, que "como la división del poder funcional se caracteriza por ordenar mediante Constitución el ejercicio del poder en una comunidad compuesta por diversas sub-comunidades"26. Estas últimas ejercen los poderes que la Constitución les reconoce de forma autónoma. De modo que "El federalismo aparece como una forma territorial de separación de los poderes políticos bajo un régimen constitucional" 27 . Este tipo de distribución de poder no implica transferencia de soberanía a los estados que la componen, pues según lo señala Friedrich, "no puede existir en un sistema federal soberanía y autonomía, estos son términos que se excluyen mutuamente" 28 .

Respecto del principio federal, este continúa definiendo este tipo de organización como "el método de distribución vertical de poderes, en la que el gobierno general y los gobiernos regionales tienen su propia esfera de actuación directa sobre el pueblo, coordinada e independiente,"29. De forma que la Constitución federal se basa

24 Ibíd. En el mismo sentido M. Jiménez De Parga, Los regímenes políticos contemporáneos, Tecnos, Madrid, 25 y ss. (1960).

25 M. J. C. Vile, en su estudio sobre constitucionalismo y separación de poderes, señala que la doctrina de separación de poderes que emerge en el siglo XVII y tiene su realización teórica y práctica en el siglo XVIII, permanece como un elemento esencial en el pensamiento constitucional, llegando a constituir un significativo rol en el concepto el constitucionalismo occidental y en los gobiernos modernos. Los teóricos han insistido en la importancia de limitar y definir el poder. La doctrina de la separación de poderes, esbozada por Locke y Monstequieu en la que cada poder debía estar en manos diferentes, da lugar a la idea del constitucionalismo moderno, en la que dicha separación de poderes solo puede lograrse mediante una Constitución. En el mismo sentido Friedrich sostiene que el constitucionalismo moderno descansa en la doctrina de la distribución de poder. Y señala que al ser el federalismo una distribución del poder político sobre base territorial mediante Constitución, el que constituye uno de los fenómenos más importantes del constitucionalismo moderno. Limited Government: A Comparison, op. cit., 13 y ss.

26 Carl J. Friedrich, Limited Government: a comparison, op. cit., 21.

27 Ibídem, 51-52. Este autor coincide en que el criterio de la soberanía como explicación de las estructuras federales debe ser abandonado, pues en este el federalismo es concebido como estructura y no como proceso.

28 Ibídem. Frente a esta premisa La Pergola sostiene que Friedrich debió tomar como base de sus estudios las estructuras diseñadas por los juristas, para señalar que la soberanía y autonomía son términos que se contraponen, acogiendo por tanto a la autonomía como el atributo que explica las situación de las subunidades en un Estado Federal. Conceptos elaborados por los teóricos alemanes del siglo XIX. La Pergola, Los nuevos senderos del federalismo, op. cit., $30-31$.

29 De esta forma C. Wheare describe el principio federal, inmerso en la Constitución de 1787. 
sobre una doble garantía: la de la independencia y viabilidad del gobierno central, y la garantía de la existencia de los gobiernos de los estados miembro ${ }^{30}$. Esto conlleva a que el tipo de poder presente en una organización federal por contraste al de una organización unitaria, en el que el poder es simple (uno en estructura, pertenece a un solo centro decisorio), se califique como un poder plural complejo "tanto en su organización misma como en sus supuestos personales y espaciales: los fines comunitarios están encomendados a un Poder federal y a varios Poderes estatales, cada uno de los cuales posee un ordenamiento constitucional propio, coexistiendo en un ámbito personal-espacial federal, los ámbitos personales espaciales correspondientes a las unidades federadas" ${ }^{31}$.

Tras esta definición, el problema en un Estado federal ya no será quién detenta la soberanía, problema en el que se centró la discusión en el siglo XIX, sino establecer un equilibrio entre la unidad y diversidad que dicha organización entraña, por una parte ${ }^{32}$, y por otra, el efectivo reparto competencial y la determinación de instrumentos de articulación de los estados miembro y la Federación ${ }^{33}$.

De este modo, el federalismo como una forma territorial de separación de los poderes políticos bajo un régimen constitucional, en el que se configura un poder plural, es concebida ${ }^{34}$ entre otros, por García Pelayo, "forma de división del poder político no solo desde el punto de vista funcional, sino sobre todo, desde el punto de vista territorial, y con arreglo al cual hay un único poder para ciertas materias y una pluralidad de poderes regionales [para otras]" 35 . Resaltando la distribución del poder, Elazar sostiene que es un modo de organización política en el que se garantiza la distribución de poder entre la autoridad nacional y sub-estatal, permitiendo compartir los procesos de decisión y de ejecución del sistema en

Federal Government, 4 ed., Oxford University Press, London, 26-27 (1963).

30 William Riker, The Development of American federalism, op. cit., 74-75.

31 M. Prelot, Institutions politiques et Droit constitutionnel, 3a ed., Dalloz, Paris, 222 y ss. en: Gurmensindo Trujillo, El federalismo español, op. cit., 18.

32 Juan José Solozabal Echevarría, El Estado autonómico como estado compuesto, Revista de Estudios Político (Nueva época), No. 110, 9-25 (oct.-dic., 2000).

33 Juan José Solozabal Echeverría, El marco constitucional del debate sobre el Estado autonómico español, Documentación Administrativa, No. 232-233, 93 (oct., 1992).

34 Se citan las definiciones del concepto de federalismo como división de poderes mediante Constitución. Pues sobre otras bases W. H. Stewart llegó a recoger 400 significados distintos del federalismo. Concepts of federalism, Lanham, Univ. Pr. of America (1984).

35 Manuel García Pelayo, Derecho constitucional comparado, Alianza Editorial, 216 (1993). 
su totalidad ${ }^{36}$. De esta forma se puede comprender la flexibilidad del Estado federal, en donde a la atribución de las funciones estatales a órganos distintos se añade la articulación del poder político también sobre base espacial ${ }^{37}$.

Ahora, la explicación concreta sobre los diversos procesos históricos de Estado federal la llevaría a cabo Friedrich, señalando que el federalismo es una idea en constante evolución, una forma dinámica de organización de poder; no se trata de un modelo estático, caracterizado por unas formas particulares y precisas de división de poderes entre diversos niveles de gobierno ${ }^{38}$, lo que explica que pueda haber múltiples formas de realizar la división del poder político y económico, así como su articulación. Era el concepto de federalismo de pacto, como lo señaló Reagan, el que concebía a este tipo estatal dentro de un concepto estático, que describe las relaciones entre el gobierno nacional y los estados como algo estacionado en el tiempo ${ }^{39}$.

Friedrich sostendría entonces que el federalismo es un proceso, esto es,

[...] el proceso de federalizar una comunidad política, mediante el cual un número de organizaciones políticas separadas, sean Estados u otro tipo de asociación, entran en arreglos para trabajar de forma conjunta decisiones, politicas y soluciones a problemas comunes. Es a la vez el proceso mediante el cual una comunidad política unitaria, se convierte en un número de unidades politicas diferenciadas, que organizadas federalmente hacen parte de un todo [...] Existe el federalismo, sólo si un grupo de comunidades políticas coexisten e interactúan como entidades autónomas, unidas en un orden común a la vez autónomo ${ }^{40}$.

Este es el concepto contemporáneo de federalismo, el que se aproxima a la organización federal de forma más realista, caracterizándola por el dinamismo ${ }^{41}$. Describe de este modo las relaciones

36 Daniel J. Elazar, State as Polities in the Federal System, National Civic Review, 77-82 (feb., 1981).

37 Guiseppe De Vergottini, Derecho constitucional comparado, Espasa - Calpe, S.A., Madrid, 265-275 (1983).

38 Carl J. Friedrich, Trends of Federalism in theory and Practice, op. cit., 7-8.

39 En el mismo sentido lo realiza Michael Reagan, The New Federalism, Oxford University Press, 3 (1972).

40 Carl J. Friedrich, Trends of Federalism in theory and Practice, op. cit., 7-8.

41 Michael D. Reagan, The New Federalism, op. cit., 3. 
al interior de una organización federal en constante cambio, las que se adecúan a las circunstancias sociales y económicas ${ }^{42}$.

La flexibilidad conceptual del federalismo se puede comprender a partir de que existen varios esquemas federales en que se da una diversa distribución de poderes. El Estado federal puede ser distinto de acuerdo a la configuración dispuesta en su Constitución $\mathrm{y}$, a la vez, puede haber Constituciones que nominen un Estado como federal sin que esta denominación se corresponda con la de este tipo de organización territorial. Es por esto que a su estudio debe integrarse su configuración empírica, observar los mecanismos políticos de una concreta organización y determinar si estos se corresponden, o no, con la organización de este tipo estatal. Es decir, debe observarse si la nominación federal coincide con la realidad de una organización; analizar una forma de organización de poder desde lo que es y no desde lo que dice $\operatorname{ser}^{43}$. Así, a modo de ejemplo, varía el federalismo de fuente anglosajona, como lo es el de los Estados Unidos, del federalismo alemán. Sus formas de configuración territorial están ancladas en la forma de ser estatal a lo largo de la historia, a los esquemas confederales que los presidieron y las fuentes conceptuales que le dieron forma ${ }^{44}$.

En este sentido, el fenómeno federal dentro de esta amplitud conceptual es una categoría del Estado, dentro del cual obra un reparto del poder político mediante Constitución y con ello se reconoce autonomía a sus subunidades (caracteres estáticos). Las diversas formas de Estado federal responderán a las circunstancias propias de cada espacio estatal. Y su evolución se presentará del cambio que presenten estas características en el tiempo, así como del cambio de las relaciones entre la Federación y los estados (caracteres dinámicos).

42 Ibíd.

43 Gumersindo Trujillo, Introducción al federalismo español, op. cit., 24. Ejemplos de sistemas que se han nominado federales: Argentina, Brasil y Venezuela, pero en la práctica las funciones entre el gobierno nacional y las unidades territoriales se realizan de acuerdo a principios de descentralización administrativa.

44 Ver al respecto: Vanessa Suelt Cock, El caso español, un proceso federal. Estudio de la nueva configuración de estados federales, Vniversitas, No. 123, 230-246 (jul.-dic., 2011). 


\section{A. Arreglos federales}

En el mundo contemporáneo debe observarse cómo se adaptan las características estructurales del Estado federal, es decir, cómo se materializan sus caracteres dinámicos. Así, pueden presentarse sistemas de financiación distintos, reconocimientos diversos de las autonomías en las unidades territoriales, funciones legislativas y administrativas con diferente operatividad, representación en el parlamento de los estados así como sistemas de coordinación y de articulación que variarán de un sistema a otro ${ }^{45}$.

En definitiva, como lo señalaría Elazar, pueden presentarse diversos arreglos federales, (federal arragement), categoría amplia con la que se describen los diversos niveles de autonomía presentes y estructuras posibles de carácter federal, que evidencian la diversidad de estructuras federales existentes en el mundo contemporáneo. Para Elazar los arreglos federales son una forma de autonomía o de auto-normación (selfrule). Existe una variedad muy amplia de arreglos federales (federal arragements) o de arreglos de autonomía (autonomy arragements) entre los cuales están las federaciones ${ }^{46}$.

Al respecto, Ferrán Requejo sostiene que una de las ventajas de los acuerdos federales es "su potencial flexibilidad y adaptación a las realidades específicas en las que habrá de actuar. Después de la Segunda Guerra Mundial la adaptabilidad a la realidad es una condición imprescindible para la estabilidad y éxito de los acuerdos federales establecidos" ${ }^{\text {47 }}$.

45 Encinar González, El Estado unitario-federal, Tecnos, 89 (1985).

46 Daniel J. Elazar, Federal Systems of the World: A Handbook of Federal, Confederal and Autonomy Arrangements, pp. xvii-xviii (1999). Son arreglos federales las federaciones (en la actualidad 17); las confederaciones (la Unión Europea); las uniones descentralizadas (los Países Bajos), los arreglos feudales transformados (feudal arrangements trasnformed. Ej: Mónaco y San Marino); los home-rule generalmente municipales, garantizados constitucionalmente; cultural home-rule, para preservar la lengua o la religión. Provincias autónomas o distritos nacionales que se desarrollaron en el mundo comunista pero que todavía existen en Nigeria. Arreglos regionales dentro de una nación como el caso de España e Italia o trasnacional como los que funcionan en el Valle del Rin; Uniones de Aduanas de uso en el Sur de África. Ligas, como Benelux, la Unión Nórdica y la Árabe; State-diasporaties, como la que funciona y une al pueblo judío; arreglos extra-territoriales como en Egipto y Sudán, que han desarrollado este sistema en las fronteras; condominios como Andorra, que ha funcionado por 700 años; estructuras estatales que funcionan a través de tribus autónomas como el caso de Afganistán.

47 Requejo Ferrán, Acomodación federal de la plurinacionalidad, asimetría federal y Estado plurinacional, en: Enric Fossa y Ferrán Requejo, Eds., El debate sobre la acomodación de la diversidad en Canadá, Bélgica y España, Trotta, Madrid, 331 (1999). 
De este modo, frente a los federalismos clásicos, los arreglos federales permiten la convivencia de diversos factores federales con otros que no lo sean, así como el reconocimiento de asimetrías. La presencia de este último elemento en los arreglos federales permite dar cauce político a gobiernos con diverso grado de autonomía y poder, presentes en ciertos contextos estatales ${ }^{48}$. Por contraste, los federalismos clásicos fueron conceptualizados sobre la base la igualdad $\mathrm{u}$ homogeneidad entre los estados federados.

\section{B. La asimetría}

El concepto de asimetría es otro de los elementos dinámicos de las realidades federales contemporáneas; fue desarrollado por Tarlton en 1965, autor que escribe que en "un sistema federal asimétrico modélico, cada unidad componente poseería una característica o un conjunto de características únicas que separaría de forma importante sus intereses de las demás o del sistema considerado en su totalidad"49. Este sistema da tratamiento a las diferencias de intereses entre estados y el carácter de cada unidad política.

El desarrollo de arreglos federales asimétricos lleva a Watts a señalar que las federaciones varían entre sí, entre otros factores por el número de unidades constituyentes y el grado de asimetría o simetría en su tamaño, características, recursos o estatus constitucional. El autor también sostiene que la asimetría (diferentes reconocimientos de poder y autonomía a las entidades sub-nacionales) es una de los más importantes características que recientemente se ha desarrollado en los regímenes federales ${ }^{50}$.

No obstante la existencia de arreglos federales asimétricos (entre otros el caso de Canadá y Bélgica ${ }^{51}$, la doctrina ha advertido que

48 Livigston, citado por Charles D. Tarton, Simetría y asimetría como elementos del federalismo: una especulación teórica, en: Enric Fossa, Ferrán Requejo, Asimetría federal y Estado plurinacional. El debate sobre la acomodación de la diversidad en Canadá, Bélgica y España, op.cit, 29.

49 Ibíd.

50 Ronald L Watts, Comparing Federal Systems, 2a ed., Queen's University and McGill-Queen's University Press, 20 (1999). En España el estudio realizado por Miguel Ángel Aparacio, en el que se analizan los casos de España, Bélgica, Canadá, Italia, y Reino Unido, se comprueba una cierta asimetría. "se da una patente diversidad interna entre las instituciones de los entes sub-centrales". La descentralización y el federalismo. Nuevos modelos de autonomía política, Cedecs, Barcelona, 269-270 (1999).

51 Requejo, Coll, Ferrán, Federalismo y grupos nacionales, la revisión de la legitimidad democrá- 
un carácter fuertemente asimétrico es indeseable ${ }^{52}$. La presencia de este elemento introduce mayor complejidad a una organización territorial, como mayores posibilidades de conflicto ${ }^{53}$. Es necesario entonces, para garantizar la existencia del Estado, un mínimo de homogeneidad estructural, competencial y financiera que permita la gobernabilidad ${ }^{54}$. Encontrar en suma un punto de equilibrio entre la necesaria simetría y las asimetrías existentes en un determinado contexto estatal ${ }^{55}$.

El aporte de los desarrollos de los arreglos y procesos federales, es comprender que es posible el reconocimiento de la asimetría en el contexto estatal, romper con el paradigma de la homogeneidad de la formulación del Estado federal en el siglo XIX y supuesto teórico relevante del Estado unitario. A su vez, advertir que el reconocimiento de la diversidad en un contexto estatal permite la gobernabilidad, manteniendo eso sí una homogeneidad estructural. En un Estado unitario hablaremos de los reconocimientos diversos de autonomía o arreglos autonómicos que implican el reconocimiento jurídico de las necesidades diversas en un marco territorial frente a las cuales no se puede responder de manera homogénea. Es el mismo sentido de los arreglos federales, pero en el Estado unitario tendrá unas características limitadas por la configuración unitaria en el territorio que se derivan de un solo poder legislativo, una sola dirección judicial, un poder ejecutivo fuerte que prevalece sobre los poderes periféricos.

tica, en: Alfons Cuco et ál., Eds., La organización territorial del Estado, España en Europa: una análisis comparado, Universitat de Valencia, 86 (2002).

52 Charles D. Tarlton, Simetría y asimetría como elementos del federalismo: una especulación teórica, op. cit., 30. Así se ha pronunciado en recientes análisis autores como Stéphane Dion, El federalismo fuertemente asimétrico: improbable e indeseable, en: Enric Fossas \& Ferrán Requejo, Asimetría federal y Estado plurinacional. El debate sobre la acomodación de la diversidad en Canadá, Bélgica y España, op. cit., 204 y ss.

53 Ronald Watts, Comparing Federal Systems, 2a ed., Queen's University and McGill-Queen's University Press, 20 (1999).

54 Encinar González, El estado federal simétrico y el fin del Estado, en: Ferrer Antonio Monreal, Coord., El Estado de las autonomías, Tecnos, Madrid, 49 y ss. (1991).

55 Javier García Roca, Asimetrías autonómicas y principio constitucional de solidaridad, II Revista Vasca de Administración Pública, No. 47, 56 (1997). 


\section{EL PROBLEMA DE LA AUTONOMÍA EN LA LEY ORGÁNICA DE ORDENAMIENTO TERRITORIAL}

En Colombia ha prevalecido una tendencia centralista, de ello dan cuenta las Constituciones de 1821, 1830, 1832, 1843 y 1886 ${ }^{56}$; fueron solo tres Constituciones las que consagraron una división del poder compuesta, las de 1853, 1858 y 1863. La Constitución de 1991 recoge la tradición unitario-centralista francesa de fuente jacobina que fuera extendida por Napoleón en Europa, y a la vez reconoce la autonomía de las entidades territoriales. Esta consagración buscaba un desarrollo "autonómico" 57 pos-constitucional, como el español, que a través de una ley orgánica determinara el diseño territorial en el marco de una estructura unitaria ${ }^{58}$. La autonomía política que reconoce la Constitución española en un Estado compuesto difiere de la autonomía que reconoce la Constitución de 1991; esta lo hace en el marco de un Estado unitario, lo que impide marcos flexibles en el diseño de esquemas territoriales autónomos, a diferencia de lo que sucede en un Estado compuesto.

Ahora bien, en el caso colombiano la pugna entre federalismo y centralismo que se presenta a lo largo del siglo XIX y que tiene como expresión normativa las Constituciones mencionadas, tiene como una de las fuentes el problema de la división del poder económico y político de forma equitativa por todos los sectores sociales del país $^{59}$. La ausencia de esa división de poder ha generado un problema territorial agudo en Colombia que se manifiesta en la ausencia de presencia estatal en territorios ${ }^{60}$, el desequilibrio en inversiones e

56 Andrés De Zubiria, Constitución y descentralización territorial, EsAP, Bogotá, 8 y ss. (1994).

57 Vanessa Suelt Cock, La organización territorial colombiana frente a la tendencia contemporánea de configuración federal, Revista de estudios socio jurídicos, op. cit. Al respecto debe tenerse en cuenta que una de las fuentes de modelo de organización territorial planteado en la Constitución de 1991 fue el artículo 137 de la Constitución española de 1978.

58 En una estructura compuesta, como es la federal, se suele reconocer autonomía política que implica potestad legislativa y competencias propias en esa materia. Ver al respecto: Vanessa Suelt Cock, El caso español, un proceso federal: estudio de la nueva configuración de estados federales, Vniversitas, No. 123, 203-246 (2011).

59 En este sentido, entre otros, Vidal Perdomo, El Estado autonómico español y el proceso de regionalización en Colombia, Revista de administración pública española, No. 155, 355-360 (2001). De Zubiría Samper, Constitución y descentralización territorial, ESAP, Bogotá, 28 (1994); Álvaro Tirado Mejía, Descentralización y centralismo en Colombia, Oveja Negra, Bogotá, 60.

60 Daniel Pecaut, Hacia la desterritorialización de la guerra y de la resistencia de la guerra, en Dimensiones territoriales de la guerra y la paz, Universidad Nacional, Red de estudios de espacio y territorio, 26 (2002). El autor da cuenta que abundante literatura en Colombia reconoce que uno de los factores del conflicto armado está ligado a la ausencia de presencia 
infraestructura y el impedimento de articular los mercados locales con los nacionales. A esta situación debe agregarse la ausencia de participación de los entes periféricos, departamentos y municipios, en los grandes temas políticos y económicos del Estado ${ }^{61}$.

Teniendo en cuenta dichas problemáticas, Colombia se inserta en la tendencia mundial global de reconocimiento de la descentralización política con el fin de modernizar el Estado; esto se impulsa con las reformas de 1968 y mediante las leyes 14 de 1983 (descentralización fiscal), 76 de 1985 (que crea los Corpes) y el Acto Legislativo $\mathrm{N}^{\circ} 1$ de 1986 (elección popular de alcaldes) ${ }^{62}$, se fortalecen las haciendas locales y se transfieren importantes competencias mediante el código municipal ${ }^{63}$. Esta tendencia se fortalecería con las discusiones sobre propuestas de organización federal y regional en el seno de la Asamblea Constituyente, así como la aprobación de los artículos que consagraban la autonomía para las entidades territoriales (art. $287 \mathrm{CP}$ ); el municipio adquiere mayor relevancia como ejecutor por excelencia de la actividad administrativa y como prestador de los servicios públicos (art. $298 \mathrm{CP}$ ), la consagración de la región como entidad administrativa y política (art. 306 y 307 $\mathrm{CP}$ ) y un régimen especial para las áreas metropolitanas, entre las más importantes consagraciones.

No obstante lo anterior, existen tres aspectos que interrumpen el fortalecimiento de las entidades municipales así como el desarrollo regional: a) las limitaciones de recursos a las entidades territoriales a partir de un marco legal en el que se privilegia la administración central de los recursos sobre la administración propia ${ }^{64}$; b) el desarrollo jurisprudencial del principio de autonomía (que privilegia

estatal en los territorios. Esta presencia no solo debe ser militar, de acuerdo con el concepto de seguridad humana "human security", sino una presencia que brinde bienestar y protección a los habitantes.

61 Darío Restrepo et ál., Diez años de descentralización: resultados y perspectivas, Fescol (1994).

62 La descentralización administrativa tendría su desarrollo en el marco de la Constitución de 1886 con las reformas constitucionales de 1905, 1910 y 1945. Jaime Vidal Perdomo, La región en la organización territorial del Estado, Centro Editorial de la Universidad del Rosario, Bogotá, 39 y ss. (2001).

63 Evaluación de la descentralización municipal en Colombia: Balance de una década, Tomo I, Marco conceptual y resultados del progreso municipal, Bogotá, Departamento de Planeación Nacional (DNP) - GTZ, Bogotá (2003).

64 Importantes normas realizan estos recortes, entre las más importantes el Acto Legislativo No. 5 de 2011 sobre regalías, la Ley 1493 de 2011 que crea en su artículo 7 una contribución parafiscal cultural a la boletería de los espectáculos públicos de las artes escénicas y hecho generador que administrará el Ministerio de Cultura. 
una autonomía de tipo administrativo) ${ }^{65}$ y c) la ley orgánica de ordenamiento territorial, que privilegia los esquemas asociativos sobre el desarrollo del principio y derecho de la autonomía y la descentralización ${ }^{66}$. Esta situación puede advertirse en las leyes que recortan transferencias, intervienen los modelos de gestión departamental y local, vuelven a centralizar recursos y extienden los controles centrales (Acto Legislativo 1 de 2001, leyes 549 de 1999 y 617 de 2000, Ley 715 de 2001, Acto legislativo 5 de 2011 sobre regalías, Ley 1493 de 2011 por la cual se toman medidas para formalizar el sector del espectáculo público de las artes escénicas), con lo cual se denota el carácter puramente administrativo de la autonomía reconocida constitucionalmente y la dependencia y subordinación de las entidades territoriales a pesar del reconocimiento de la autonomía constitucional.

Ahora bien la Ley de Ordenamiento Territorial (LOOT), podía haber desarrollado la autonomía administrativa, proponiendo un diseño regional que se acerca más al modelo francés de la década de los ochenta que al español que tiene características políticas cercanas a las federales ${ }^{67}$. No obstante lo anterior, la actual ley de ordenamiento territorial — LOOT_, Ley 1454 de 2011, frustró la intención de los constituyentes de otorgar mayor autonomía a las entidades sub-estatales de un Estado y romper con la tradición centralista que ha generado desequilibrios económicos entre territorios, así como guiar la interpretación constitucional que reconoció la

65 Ver al respecto la línea jurisprudencial trazada en el artículo de Vanessa Suelt Cock et ál., $L a$ autonomía local en diversos sistemas de organización un marco conceptual para el análisis del caso colombiano, op. cit., que contiene las siguientes sentencias de la Corte Constitucional, Sentencia C-517/92, 15 de septiembre de 1992, Magistrado Ponente Ciro Angarita-Barón. Sentencia C-004/93, 14 de enero de 1993, Magistrado Ponente Ciro Angarita-Barón. Sentencia C-497 A/94, 3 de noviembre de 1994, Magistrado Ponente Vladimiro Naranjo-Mesa. Sentencia C-535/96, 16 de octubre de 1996, Magistrado Ponente Alejandro Martínez-Caballero. Corte Constitucional, Sentencia C-219/97, 24 de abril de 1997, Magistrado Ponente Eduardo Cifuentes-Muñoz. Sentencia C-346/97, 22 de julio de 1997, Magistrado Ponente Antonio Barrera-Carbonell.

66 Liliana Estudian Achury, Desequilibrios territoriales, estudio sobre la descentralización y el ordenamiento territorial colombiano. Una mirada desde el nivel intermedio de gobierno, Ediciones Doctrina y Ley - Universidad del Rosario, 284.

67 Así también lo ha sostenido el profesor Vidal Perdomo en El Estado autonómico español y el proceso de regionalización en Colombia, op. cit., 355-360. Posición que sostendría también en la publicación con el mismo título en Revista Iberoamericana de Administración Pública, RIAP, 209-216 (2001), recogida en La región en la organización territorial del Estado, op. cit. Ver: Vanessa Suelt Cock, La organización territorial colombiana frente a la tendencia de configuración federal, op. cit. 
autonomía solo de tipo administrativo. Las disposiciones actuales de la LOOT permitirán que se continúe afectando las agendas locales en materia económica, y que los entes del Estado no tengan maniobra política si se apartan de las directrices establecidas por el ejecutivo central. La consagración de las regiones como entidades de índole administrativa y planificación que no tienen las características regionales indicadas en los reforzamientos regionales de otros Estados como el francés, el Estado unitario por excelencia, permite una maniobra poco flexible frente a reconocimientos de autonomía diversos.

Este esquema deja un margen muy pequeño a desarrollos políticos y económicos diversos del establecido desde el nivel central, o por lo menos permitir su participación en las grandes decisiones políticas económicas del Estado; será muy difícil para las regiones más pobres aliarse políticamente para expandir las inversiones de infraestructura que están concentradas en las más importantes ciudades colombianas. En suma, se privilegian esquemas asociativos que solo les puede ser útil a pocas ciudades colombianas (Bogotá, Barranquilla, Cali...) y se deja sin opciones al resto de la territorialidad colombiana, lo cual, desde un marco normativo, generará o profundizará las brechas económicas y sociales entre territorios.

Este esquema se puede explicar desde las características estáticas del Estado unitario colombiano ancladas en concretas circunstancias históricas que dieron lugar a la Constitución de 1886 y al reconocimiento posterior de la autonomía administrativa ${ }^{68}$. Respecto a las características dinámicas de la organización territorial, puede observarse una forma de configuración diversa en los territorios que no responden al marco normativo y que tienen un acento cada vez más independiente ${ }^{69}$.

68 Liliana Estupiñan Achury, Desequilibrios territoriales, estudio sobre la descentralización y el ordenamiento territorial colombiano, op. cit., 88-111.

$69 \mathrm{Al}$ respecto, diferente literatura ha señalado que ello ha tenido lugar gradualmente a partir de la Constitución de 1991 que reconocía una autonomía más amplia, eso sí, en el marco de un Estado unitario. Darío Restrepo et ál., El estado del arte de la descentralización política y de la oferta pública en participación ciudadana, en: Ariel Cifuentes Noyes et ál., Diez años de descentralización: resultados y perspectivas, Fundación Friedrich Ebert de Colombia, Santafé de Bogotá (1994). Clara López Obregón, Control fiscal territorial: fundamentos de reforma. Facultad de jurisprudencia, Universidad del Rosario, Bogotá, 35 y ss. (2006). 


\section{A MODO DE CONCLUSIÓN: LA SUPERACIÓN DE LA RIGIDEZ DEL ESTADO UNITARIO, LA ALTERNATIVA AUTONÓMICA DE LOS TERRITORIOS DIVERSOS}

Si se comprende la idea del proceso en la configuración de los diseños territoriales, aun en esquemas tan rígidos como el de un Estado unitario, puede percibirse que existen movimientos hacia la regionalización que comprenden el reconocimiento de la diversidad a las comunidades que conforman el Estado y la participación, articulación y coordinación de las decisiones entre la entidad central y las entidades periféricas. Elazar, al respecto, señalaba que la organización territorial comprende diversos niveles de gobierno, cada uno con sus propias esferas para llevar a cabo sus propios asuntos. Es una matriz que necesita de canales para cooperar y tomar decisiones conjuntas para resolver problemas comunes.

En este escenario, los elementos de cooperación son fundamentales. En los esquemas federales, por ejemplo, existen múltiples mecanismos de cooperación en Estados Unidos, entre otros, el Governor's Conference, integrada por los gobernadores de los estados, instancia en la que se toman decisiones de cooperación entre los estados, así como posiciones unánimes para que esta la represente frente a la Federación. En 1933 se crea el Council of States Governments, en donde participan todos los estados de la Unión. En esta instancia se toman decisiones conjuntas entre la Federación y los estados sobre temas conjuntos en materia de legislación, administración y temas judiciales, así como decisiones de cooperación entre estados. Existen a su vez otros órganos en los que se toman decisiones en torno a una regulación común, creación de órganos ejecutivos y coordinación de la actividad administrativa y judicial ${ }^{70}$. En Alemania los esquemas de cooperación son complejos, y comprenden órganos, mecanismos financieros e instancias de toma de decisiones. El modelo cooperativo, a su vez, está inscrito en la Constitución artículos 91.a y b., así como en el artículo 104 a. GG, las cuales

70 Tales como la Conferencia Nacional de Comisionados para la Uniformización de Leyes Estatales (National Conference of Commissioners on Uniform State Laws); la Conferencia de los Jefes de Justicia (Conference of Chief Justices); la Conferencia Nacional Legislativa (National legislative Conference) y la Asociación Nacional de Oficiales de Presupuesto Estatal (National Association of State Budget Officer). 
insertan formalmente el término cooperación e institucionalizan prácticas cooperativas. De acuerdo con los artículos mencionados, la Federación cooperará para el cumplimiento de las tareas de los estados, cuando sea importante para el conjunto, y para mejorar las condiciones de vida de los habitantes en las siguientes áreas: construcción y ampliación de escuelas técnicas, mejora de la estructura económica regional y de las estructuras agrarias. En dichas áreas la regulación por ley federal, requerirá de la aprobación de la Cámara de los estados miembro (Bundesrat). La cooperación entre los länder se efectúa por medio de tratados, convenios administrativos y subvenciones condicionadas. Mientras tanto, las decisiones sobre cooperación se llevan a cabo en la conferencias de presidentes y ministeriales, entre otras instituciones comunes. El objetivo es una acción concertada para la preservación o creación de condiciones equivalentes de vida ${ }^{71}$.

La existencia de estos mecanismos permite comprender, como se ha señalado en este escrito, la gran flexibilidad del Estado federal, en donde las decisiones se concertan y para ello existen esquemas de toma de decisiones de índole incluso legislativo, financiero, de orden público, etc. En el caso colombiano su flexibilidad se presenta, tímidamente, en la configuración de la autonomía política que reconoce la diversidad y pluralidad territorial para las entidades territoriales indígenas, que ya cuenta con reconocimiento constitucional y legal, pero no fue objeto de regulación por parte de la LOOT; los territorios de los afrodescendientes ${ }^{72}$ y las zonas de reserva campesina ${ }^{73}$, pero a su vez, con todos los esquemas de direccionamiento político alterno o complementario a las políticas nacionales, los canales de cooperación como reuniones de alcaldes o gobernadores y los esquemas para tomar decisiones comunes. Su reconocimiento normativo, en términos de Jellinek, da cuenta

71 Benda, Maihofer, Vogel, Hesse, Heyde, Manual de derecho constitucional, op. cit., 667.

72 Los reconocimientos de los territorios colectivos Ley 70 de 1993, art. 1', "[...] ley tiene por objeto reconocer a las comunidades negras que han venido ocupando tierras baldias en las zonas rurales ribereñas de los ríos de la Cuenca del Pacífico, de acuerdo con sus prácticas tradicionales de producción, el derecho a la propiedad colectiva".

73 Ley 60 de 1994, artículo $1^{\circ}$ "[...] Regular la ocupación y aprovechamiento de las tierras baldias de la Nación, dando preferencia en su adjudicación a los campesinos de escasos recursos, y establecer Zonas de Reserva Campesina para el fomento de la pequeña propiedad rural, con sujeción a las políticas de conservación del medio ambiente y los recursos naturales renovables y a los criterios de ordenamiento territorial y de la propiedad rural que se señalen”. 
de la realidad estatal sobre los dogmas constitucionales, los que deben adaptarse a las necesidades en curso: la diversidad presente en el territorio colombiano y la necesidad de concertación. Su desarrollo reglamentario, puede permitir el afianzamiento de los acuerdos de $\operatorname{paz}^{74}$ y la flexibilidad del diseño territorial para lograr el equilibrio económico entre territorios. Es importante en este sentido institucionalizar mecanismos de cooperación entre el nivel nacional, los departamentos y los municipios para mejorar la toma de decisiones conjuntas, y también determinar cómo enfrentar problemas comunes.

En ello es fundamental comprender el concepto de autonomía como un poder de dirección política "prefigurado por la propia Constitución que es la que contiene el diseño conforme al cual se reparte los poderes de dirección política y sus limitaciones respectivas" 75 . En el caso colombiano, la Constitución reconoce las entidades territoriales indígenas, los territorios colectivos y la equidad en el acceso a la propiedad, base de la zona de la reserva campesina. Pero también reconoce esta autonomía política a ciudades como Bogotá, entre otras.

Frente al Estado centralizado, la autonomía se afirma así como un principio de organización del poder definido constitucionalmente como "principio general moderado y completado por la solidaridad, en el cuadro de una unidad indivisible" 76 . Los conceptos de autonomía como derecho y como principio organizacional del Estado no son contrapuestos sino complementarios, manifiestan la voluntad de organizar el poder por la vía de una descentralización territorial cuyo sentido político viene dado por la capacidad de dirigir su propia actividad en el ámbito reconocido por la Constitución y las leyes ${ }^{77}$.

74 Esta afirmación se desprende del análisis realizado entre otros autores por Thomas Fischer, Colombia: Estado débil sin territorialidad entera. Una visión histórica; y los demás artículos de Miguel Borja, Normando Suárez, José Oswaldo Espinosa, Ismael Sánchez, en: Dimensiones territoriales de la guerra y la paz, op. cit., 213-316.

75 Ignacio De Otto Pardo, Estudios sobre derecho estatal y autonómico, Civitas, 22 (1996).

76 Luis Sánchez Agesta, Comentarios al art. $2^{\circ}$ en Constitución española, Edición comentada, Centro de Estudios Constitucionales, Madrid, 109 (1979). La autonomía se manifiesta entonces dentro del principio de unidad, constituye el límite de la autonomía. Esta unidad se manifiesta en la indisolubilidad e indivisibilidad de la Nación, vinculada a una única soberanía que reside en el pueblo español. Santiago Muñoz Machado, Los principios constitucionales de unidad y autonomía, Revista de Administración Pública, Nos. 100-102, 1840 y ss. (1983).

77 José Antonio Alonso de Antonio, Derecho constitucional español, 2a . Ed., Universitas, Madrid, 285 y ss. (1998). 
Debe destacarse que este concepto de autonomía desarrollado por la doctrina italiana y recogido por la española hace referencia no solo a la facultad de gobernarse por sus propias autoridades para defender y promover los intereses propios de un marco subestatal, sino a la capacidad de reconocer dichos intereses, como lo señala Tomas Fischer: actuar en el marco legal para la defensa de intereses colectivos y no solo personales ${ }^{78}$. Así también, encontrar esquemas de articulación entre políticas nacionales y locales, mecanismos de cooperación y solidaridad. En el siglo XXI Colombia sigue enfrentado esta problemática, los esquemas de articulación, cooperación y de solidaridad son escasos en la matriz estatal. Esto no es un fenómeno propio del sector político colombiano, se presenta en otras latitudes, pero acá reviste un matiz dramático al ver que ello conlleva a la desprotección de los derechos fundamentales de la población. La solución puede ser incrementar esos canales de comunicación entre entidades territoriales y el gobierno nacional que permitan una comprensión de la realidad estatal y atender los problemas que son detectados como vitales para todas las entidades territoriales de forma mancomunada.

Frente a este planteamiento debe destacarse la defensa de intereses territoriales por parte de las comunidades indígenas, los afrocolombianos y las zonas de reserva campesina; estas alternativas que denomino autonómicas, por privilegiar el principio de la autonomía en estos marcos locales, se destacan porque existe una apuesta por identificar los intereses locales que responde a la necesidad de reconocimientos colectivos para mejorar el gobierno de los territorios, no sin obstáculos, por supuesto. También adquieren un papel político de negociación frente al gobierno local (departamentos y municipios a los que pertenece) y frente al nivel nacional. En este tipo de gobiernos se presentan y pueden profundizarse alternativas de cooperación con estos gobiernos; alternativas productivas y de desarrollo que reconozcan sus tradiciones, esquemas de negociación y concertación que pueden extenderse a las demás entidades territoriales en un marco más cooperativo. En el caso de la zona de reserva campesina, se trata de una deuda con un sector tradicionalmente desprotegido por los gobiernos, la población campesina,

78 Fischer llama la atención sobre la debilidad del Estado colombiano en el que las autoridades no acatan el marco legal y defienden sus intereses personales. Ibíd. 
que tiene una apuesta común e intereses propios que los diferencian y los unen en una alternativa de gobierno, de participación en la política y de mecanismos alternativos de desarrollo, que dejados al mercado, sin regulación, pueden crear un desequilibrio estatal que ponga en cuestionamiento los futuros acuerdos de paz.

En suma, privilegiar el principio de la autonomía en estas alternativas romperá la rigidez propia del Estado colombiano tradicionalmente centralista y unitarista para abrirse a la tendencia global de descentralización que se afianza en los reconocimientos de las identidades locales, de la asimetría presente en un Estado y de los equilibrios entre la unidad y la diversidad que un Estado engloba. Estos reconocimientos permiten a su vez crear esquemas de cooperación y de solidaridad con el Estado central. Ahora, ello puede ir de la mano con la creación de regiones administrativas, en las que se creen las condiciones para desarrollar las regiones políticas, en las que de nuevo el principio de la autonomía puede jugar un papel fundamental para dejar en manos de las poblaciones la conducción de sus intereses políticos y su desarrollo económico. Acá la idea de proceso en el diseño territorial como institución no acabada es nuclear, en la continua tarea de encontrar alternativas, mecanismos, que rompan con la rigidez y la homogeneidad del Estado unitario colombiano; ello permitirá una constante búsqueda por relacionarse mejor entre territorios y el centro, solucionar problemas comunes que van más allá de esquemas asociativos y que implican materializar la idea de la concertación y la negociación. 


\section{BIBLIOGRAFÍA}

Álvaro Tirado Mejía, Descentralización y centralismo en Colombia, Oveja Negra, Bogotá (1983).

Andrés De Zubiria, Constitución y descentralización territorial, EsAP, Bogotá, 8 y ss. (1994).

Arthur W. Macmahon, Federalism: Nature and emergent, Garden City, New York, Doubleday (1955).

C. Wheare, Federal Government, 4 ed., Oxford University Press, London (1963).

Carl J. Friedrich, Limited Government: a comparison, Harvard University - PrenticeHall, Inc - Englewood Cliffs, New Jersey (1974).

Clara López Obregón, Control fiscal territorial: fundamentos de reforma. Facultad de jurisprudencia, Universidad del Rosario, Bogotá (2006).

Daniel Elazar, Federal systems of the world: a handbook of federal, confederal and autonomy arrangements, Jerusalem Institute for Federal Studies; Comp. and Ed. Daniel J. Elazar, London-Longman (1991).

, Federalism: An Overview, Pretoria, 19 (1995).

Daniel Pecaut, Hacia la desterritorialización de la guerra y de la resistencia de la guerra, en: Dimensiones territoriales de la guerra y la paz, Universidad Nacional, Red de estudios de espacio y territorio, 26 (2002).

Darío Restrepo et ál., Diez años de descentralización: resultados y perspectivas, Fescol (1994).

De Zubiría Samper, Constitución y descentralización territorial, Constitución y descentralización territorial, ESAP, Bogotá (1994).

Departamento de Planeación Nacional (DNP) - GTZ, Balance de una década, Tomo I, Marco conceptual y resultados del progreso municipal, Bogotá, Departamento de Planeación Nacional (DNP) - GTZ, Bogotá (2003).

Encinar González, El Estado unitario-federal, Tecnos, 89 (1985).

Guiseppe De Vergottini, Derecho constitucional comparado, Espasa -Calpe, S.A., Madrid, 265-275 (1983).

Hans Gerd Pieper, Staatsorganisationsrecht, Alpmann Schmidt, Auflage (2007).

Ignacio De Otto Pardo, Estudios sobre derecho estatal y autonómico, Civitas (1996).

Jaime Vidal Perdomo, La región en la organización territorial del Estado, Centro Editorial de la Universidad del Rosario, Bogotá (2001).

José Antonio Alonso de Antonio, Derecho constitucional español, 2a. Ed., Universitas, Madrid, 285 y ss. (1998).

Liliana Estupiñan Achury, Desequilibrios territoriales, estudio sobre la descentralización y el ordenamiento territorial colombiano. Una mirada desde el nivel intermedio de gobierno, Ediciones Doctrina y Ley - Universidad del Rosario, Bogotá (2012).

Luis Sánchez Agesta, Comentarios al art. $2^{\circ}$ en Constitución española, Edición 
comentada, Centro de Estudios Constitucionales, Madrid (1979).

M. Jiménez De Parga, Los regímenes políticos contemporáneos, Tecnos, Madrid (1960).

M. Prelot, Institutions politiques et Droit constitutionnel, 3a ed., Dalloz, París (1963).

Manuel García Pelayo, Derecho constitucional comparado, Alianza Editorial (1993).

Michael Reagan, The New Federalism, Oxford University Press, 3 (1972).

Miguel Ángel Aparacio, La descentralización y el federalismo. Nuevos modelos de autonomía política, Cedecs, Barcelona (1999).

Ronald L Watts, Comparing Federal Systems, 2a ed., Queen's University and McGillQueen's University Press, Ontario (1999).

Vanessa Suelt Cock, El federalismo en teoría y práctica, el caso español un proceso federal, Juruá editores (2010).

Vergottini, Derecho Constitucional Comparado, Espasa-Calpe, Madrid (1983).

W. H. Stewart, Concepts of federalism, Lanham, Univ. Pr. of America (1984).

\section{Contribuciones en obras colectivas}

Charles D'Tarton, Simetría y asimetría como elementos del federalismo: una especulación teórica, en: Enric Fossa \& Ferrán Requejo, Asimetría federal y Estado plurinacional. El debate sobre la acomodación de la diversidad en Canadá, Bélgica y España, Editorial Trotta (1999).

D. Tarton, Simetría y asimetría como elementos del federalismo: una especulación teórica, en: Enric Fossa \& Ferrán Requejo, Asimetría federal y Estado plurinacional. El debate sobre la acomodación de la diversidad en Canadá, Bélgica y España, Trotta (1999).

Darío Restrepo et ál., El estado del arte de la descentralización política y de la oferta pública en participación ciudadana, en: Ariel Cifuentes Noyes et ál., Diez años de descentralización: Resultados y perspectivas, Fundación Friedrich Ebert de Colombia, Santafé de Bogotá (1994).

Encinar González, El estado federal simétrico y el fin del Estado, en: Ferrer Antonio Monreal, Coord., El Estado de las autonomías, Tecnos, Madrid, 49 y ss. (1991).

La Pergola, Federalismo y regionalismo: el caso italiano, en: Gumersindo Trujillo, Coord., Federalismo y regionalismo, Centro de Estudios Constitucionales, Madrid, 165-196 (1979)

Peter Häberle, El regionalismo como principio estructural naciente del Estado constitucional y como máxima de la política del derecho europeo, en: Iñaki Herrarte Lasagabaster, Ed., Retos actuales del Estado constitucional, Instituto Vasco de Administración Pública, Oñati (1996).

Requejo Ferrán, Acomodación federal de la plurinacionalidad, Asimetría federal y Estado plurinacional, en: Enric Fossa \& Ferran Requejo, Eds., El debate sobre la acomodación de la diversidad en Canadá, Bélgica y España, Trotta, Madrid (1999).

Requejo, Coll, Ferrán, Federalismo y grupos nacionales, la revisión de la legitimidad 
democrática, en: Alfons Cuco et ál., Eds., La organización territorial del Estado, España en Europa: una análisis comparado, Universitat de Valencia (2002).

Stéphane Dion, El federalismo fuertemente asimétrico: improbable e indeseable, en: Enric Fossas \& Ferrán Requejo, Asimetría federal y Estado plurinacional. El debate sobre la acomodación de la diversidad en Canadá, Bélgica y España, Trotta, 204 y ss. (1999).

Thomas Fischer, Colombia: Estado débil sin territorialidad entera. Una visión histórica, en: Dimensiones territoriales de la guerra y la paz, Universidad Nacional, Red de estudios de espacio y territorio, 213-316 (2002).

\section{Revistas}

Daniel Elazar, From Statism to Federalism A paradigm Shift, 17 International Political Science, No. 4, 417-429 (1996).

-, State as Polities in the Federal System, National Civic Review, 77-82 (febrero de 1981).

Javier García Roca, Asimetrías autonómicas y principio constitucional de solidaridad, II Revista Vasca de Administración Pública, No. 47, 56 (1997).

Juan José Solozabal Echevarria, El Estado autonómico como estado compuesto, Revista de Estudios Políticos (Nueva época), No. 110, 9-25 (octubre-diciembre del 2000).

Juan José Solozabal Echeverria, El marco constitucional del debate sobre el Estado autonómico español, Documentación Administrativa, No. 232-233, 93 (octubre de 1992).

Santiago Muñoz Machado, Los principios constitucionales de unidad y autonomía, Revista de Administración Pública, Nos. 100-102, 1840 y ss. (1983).

Vanessa Suelt Cock, La influencia del federalismo competitivo en el nuevo régimen local español, 12 Revista de estudios socio jurídico, No. 1, Universidad del Rosario, Bogotá, 199-232 (2010).

, El caso español, un proceso federal. Estudio de la nueva configuración de estados federales, Vniversitas, No. 123, 230-246 (julio-diciembre del 2011).

La organización territorial colombiana frente a la tendencia de configuración federal, 10 Revista de Estudios Socio Jurídico, No. 1, 155-200 (2008).

Vanessa Suelt Cock et. ál., La autonomía local en diversos sistemas de organización, un marco conceptual para el análisis del caso colombiano, Vniversitas, No. 122, 117-168 (2011).

Vergottini, Regiones y Estado en la dinámica institucional. Consideraciones comparadas, Revista Vasca de Administración Pública, No. 14, 8 y ss. (1986).

Vidal Perdomo, El Estado autonómico español y el proceso de regionalización en Colombia, en Revista de Administración Pública Española, No. 155, 355-360 (2001). 


\section{Jurisprudencia colombiana}

Corte Constitucional, Sentencia C-517/92, 15 de septiembre de 1992. M.P. Ciro AngaritaBarón.

Corte Constitucional, Sentencia C-004/93, 14 de enero de 1993. M.P. Ciro AngaritaBarón.

Corte Constitucional, Sentencia C-497 A/94, 3 de noviembre de 1994. M.P. Vladimiro Naranjo-Mesa.

Corte Constitucional, Sentencia C-535/96, 16 de octubre de 1996. M.P. Alejandro Martínez-Caballero.

Corte Constitucional, Sentencia C-219/97, 24 de abril de 1997. M.P. Eduardo CifuentesMuñoz.

Corte Constitucional, Sentencia C-346/97, 22 de julio de 1997. M.P. AntonioBarreraCarbonell

\section{Leyes}

Acto legislativo No. 5 de 2011. Por el cual se constituye el Sistema General de Regalías, se modifican los artículos 360 y 361 de la Constitución Política y se dictan otras disposiciones sobre el Régimen de Regalías y Compensaciones.

Acto Legislativo número 1 de 2001. Por medio del cual se modifican algunos artículos de la Constitución Política.

Ley 1122 de 2007. Por la cual se hacen algunas modificaciones en el Sistema General de Seguridad Social en Salud y se dictan otras disposiciones, 9 de enero de 2007, 46.506Diario Oficial, 9 de enero de 2007.

Ley 1176 de 2007. Por la cual se desarrollan los artículos 356 y 357 de la Constitución Política y se dictan otras disposiciones, 27 de diciembre de 2007

Ley 1454 de 2011. Ley Orgánica de Ordenamiento Territorial

Ley 1493 de 2011. Por la cual se toman medidas para formalizar el sector del espectáculo público de las artes escénicas

Ley 549 de 1999. Por la cual se dictan normas tendientes a financiar el pasivo pensional de las entidades territoriales, se crea el Fondo Nacional de Pensiones de las entidades territoriales y se dictan otras disposiciones en materia prestacional, 28 de diciembre de 1999.

Ley 60 de 1994. Por la cual se crea el Sistema Nacional de Reforma Agraria y Desarrollo Rural Campesino, se establece un subsidio para la adquisición de tierras, se reforma el Instituto Colombiano de la Reforma Agraria y se dictan otras disposiciones.

Ley 617 de 2000. Por la cual se reforma parcialmente la Ley 136 de 1994, el Decreto Extraordinario 1222 de 1986, se adiciona la ley orgánica de presupuesto, el Decreto 1421de 1993, se dictan otras normas tendientes a fortalecer la descentralización, y se dictan normas para la racionalización del gasto público 
nacional, 6 de octubre de 2000.

Ley 70 de 1993. Por la cual se desarrolla el artículo transitorio 55 de la Constitución Política.

Ley 715 de 2001. Por la cual se dictan normas orgánicas en materia de recursos y competencias de conformidad con los artículos 151, 288, 356 y 357 (Acto Legislativo 01 de 2001) de la Constitución Política y se dictan otras disposiciones para organizar la prestación de los servicios de educación y salud, entre otros, 21 de diciembre de 2001.

Ley 819 de 2003. Por la cual se dictan normas orgánicas en materia de presupuesto, responsabilidad y transparencia fiscal y se dictan otras disposiciones,

Ley 850 de 2003. Por medio de la cual se reglamentan las veedurías ciudadanas, 18 de noviembre.

Ley 863 de 2003. Por la cual se establecen normas tributarias, aduaneras, fiscales y de control para estimular el crecimiento económico y el saneamiento de las fianzas públicas, 29 de diciembre de 2003 
